\title{
Galloping Stability and Wind Tunnel Test of Iced Quad Bundled Conductors considering Wake Effect
}

\author{
Xiaohui Liu, ${ }^{1,2}$ Ming Zou $\left(\mathbb{D},{ }^{2}\right.$ Chuan Wu, ${ }^{3}$ Mengqi Cai, ${ }^{4}$ Guangyun Min $\mathbb{D}^{2}$, \\ and Shuguang Yang ${ }^{2}$ \\ ${ }^{1}$ State Key Laboratory of Mountain Bridge and Tunnel Engineering, Chongqing Jiaotong University, Chongqing 400074, China \\ ${ }^{2}$ College of Civil Engineering, Chongqing Jiaotong University, Chongqing 400074, China \\ ${ }^{3}$ State Grid Henan Electric Power Research Institute, Zhengzhou 450052, China \\ ${ }^{4}$ College of Architecture and Civil Engineering, Chengdu University, Chengdu 610106, China
}

Correspondence should be addressed to Ming Zou; 622180970089@mails.cqjtu.edu.cn

Received 26 September 2020; Revised 28 October 2020; Accepted 3 November 2020; Published 21 November 2020

Academic Editor: Manuel De la Sen

Copyright ( $\odot 2020$ Xiaohui Liu et al. This is an open access article distributed under the Creative Commons Attribution License, which permits unrestricted use, distribution, and reproduction in any medium, provided the original work is properly cited.

A new quad bundle conductor galloping model considering wake effect is proposed to solve the problem of different aerodynamic coefficients of each subconductor of iced quad bundle conductor. Based on the quasistatic theory, a new 3-DOF (three degrees of freedom) galloping model of iced quad bundle conductors is established, which can accurately reflect the energy transfer and galloping of quad bundle conductor in three directions. After a series of formula derivations, the conductor stability judgment formula is obtained. In the wind tunnel test, according to the actual engineering situation, different variables are set up to accurately simulate the galloping of iced quad bundle conductor under the wind, and the aerodynamic coefficient is obtained. Finally, according to the stability judgment formula of this paper, calculate the critical wind speed of conductor galloping through programming. The dates of wind tunnel test and calculation in this paper can be used in the antigalloping design of transmission lines.

\section{Introduction}

Under wind load, self-excited vibration of iced transmission lines with low frequency and large amplitude easily occurs. Atmospheric icing on conductor is an important factor that determines the galloping of transmission lines, and it is also very difficult to prevent icing of transmission lines. When galloping occurs, the transmission line will produce a large amplitude vibration, sometimes the amplitude reaching 1$2 \mathrm{~m}$. Due to the large amplitudes, galloping can eventually lead to the wear and damage of hardware, the loose and falloff of bolts, the damage of spacer bars, the break of transmission line, and even the collapse of transmission tower; the power system will be shut down [1].

Considering the vertical vibration, Den Hartog proposed the vertical galloping theory [2]. Parkinson, Novak, and Iwan improved the vertical theory [3-5]. Nigol proposed the theory of torsional galloping considering the coupling effect [6]. P Yu proposed the eccentric inertial coupling galloping theory [7].
On the basis of the three galloping theories, experts and scholars all over the world have done a lot of research work. Blevens and Iwan [8] studied the coupling of crosswind and torsional galloping, and then Jones studied the two degrees of freedom galloping of crosswind and crosswind [9]. Luongo et al. established a cable model considering torsion factors. Turn the flexible classical equation into another governing equation $[10,11]$. Yang et al. studied the bearing capacity curve of tower considering the interaction of turbulent wind and tower line in the tower line system [12]. Aboshosha and El Damatty derived the closed solution to calculate the reaction force of conductor under downburst load [13, 14]. Chiradeja and Ngaopitakkul discussed the different behaviors of transmission system in case of lightning strike, fault, and other disturbances [15]. Stoyanoff used a 3-DOF model to study the stability of cable under wind load [16]. Wu et al. proposed a new full-scale reconstruction method of transmission line curve based on attitude sensor [17]. 
In the aspect of conductor mode and frequency, when considering the mode and natural frequency of single span transmission line, many literatures have studied its parametric vibration [18-20]. Liu et al. put forward an improved mathematical model to study the coupling characteristics of multispan transmission lines. Based on the solution method of single span cable, the dynamic stiffness expression of double span transmission line with arbitrary dip angle is derived [21, 22]. Tokoro et al. studied the instability caused by galloping [23].

To sum up, previous studies focused on the use of numerical simulation method; the conclusions do not have universal applicability. According to what the authors know, squaring up the air wake effect, the galloping mechanical model of the iced quad bundle conductors with 3-DOF has not been studied. Based on the quasistatic theory, this paper establishes a galloping model of iced quad bundle conductors with 3-DOF, considers the influence of wake effect on the aerodynamic force of each subconductor, and theoretically deduces the stability judgment of transmission line system. In the wind tunnel test, the galloping of iced quad bundle conductors is simulated accurately under different conditions. The aerodynamic coefficients are obtained by wind tunnel test, which can be used to analyze the aerodynamic characteristics of conductor. Finally, the critical wind speed is calculated according to the stability formula. The results of this paper can be used in the design of conductor antigalloping.

\section{Method and Model}

The transmission line usually takes place in the open area. The height of the overhead transmission line from the ground is large, and the influence of the ground object on the wind speed is very small, so the mechanical galloping model in this paper is established under the static wind. Due to the influence of wake effect, the quad bundled conductor is in the wind field with uneven wind speed, and the aerodynamic force of each subconductor is different. When calculating the whole wind load of the quad bundled conductor, whole wind load cannot be equivalent to four times of the wind load of one subconductor. In this paper, the wind speed along the transmission line direction is assumed not to change. We believe that the shape and thickness of the ice on the transmission line are constant along the conductor direction. Based on the above assumptions, the complex model of galloping of iced conductor can be simplified. The modal truncation method is used to transform the partial differential equations of continuous medium vibration into ordinary differential equations along three cross-sectional directions. The 3-DOF model of vibration stability analysis is shown in Figure 1.

The wind speed is $U$. The constraint stiffness of quad bundled conductor in horizontal direction, vertical direction, and torsional direction is $K_{z}, K_{y}$, and $K_{\theta}$, respectively. $R$ is the distance between the center of subconductor and the center of bundled conductor. $\alpha_{0}$ is the initial attack angle. $\theta$ is a dynamic rotation angle, which changes with time. Since the torsional center is also the geometric center of the quad bundled conductor, the dynamic angle of each subconductor is $\theta$. The coordinates of the cross-section center of the subconductor in the whole coordinate system are

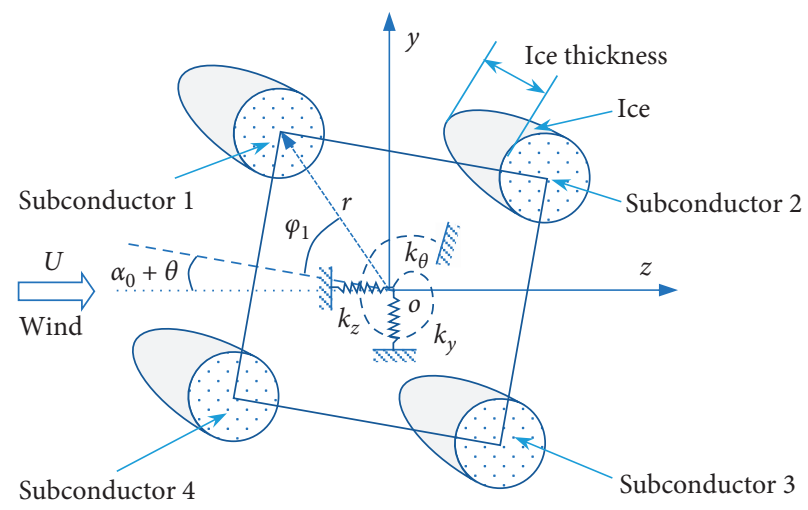

Figure 1: Mechanical model of iced quad bundled conductors.

$$
\begin{aligned}
& y_{i(t)}=y+r \sin \left(\alpha_{0}+\varphi_{i}+\theta\right), \\
& z_{i(t)}=z-r \cos \left(\alpha_{0}+\varphi_{i}+\theta\right),
\end{aligned}
$$

where $y, z$ is the coordinate value of the center of quad bundled conductor in the whole coordinate system and $i$ is the number of bundle conductors. For this paper, $i$ takes 1, 2, 3 , and $4 . \varphi_{i}$ is the angle between connecting line of center of the bundled conductor and the central of the subconductor and the horizontal spacer; the value is

$$
\begin{aligned}
& \varphi_{1}=45^{\circ}, \\
& \varphi_{2}=135^{\circ}, \\
& \varphi_{3}=225^{\circ}, \\
& \varphi_{4}=315^{\circ} .
\end{aligned}
$$

The displacement of the subconductor changes with time can be expressed as

$$
\begin{aligned}
& v_{i(t)}=v+r\left(\sin \left(\alpha_{0}+\varphi_{i}+\theta\right)-\sin \left(\alpha_{0}+\varphi_{i}\right)\right), \\
& u_{i(t)}=u-r\left(\cos \left(\alpha_{0}+\varphi_{i}+\theta\right)+\cos \left(\alpha_{0}+\varphi_{i}\right)\right) .
\end{aligned}
$$

In the formula, $v, u$ are the $y$ direction and $z$ direction displacements of the quad bundled conductor, respectively. The first derivative of the displacement of the subconductor is obtained, and the velocity of the subconductor is

$$
\begin{aligned}
& \dot{v}_{i(t)}=\dot{v}+r \dot{\theta} \cos \left(\alpha_{0}+\varphi_{i}+\theta\right), \\
& \dot{u}_{i(t)}=\dot{u}+r \dot{\theta} \sin \left(\alpha_{0}+\varphi_{i}+\theta\right),
\end{aligned}
$$

where the upper punctuation represents the derivation of time. Due to the relative motion of the conductor under the wind load, the lift force is not along the vertical direction; the drag force of the conductor is not along the horizontal direction. The orientation of lift force and drag force will make an angle with the vertical or horizontal direction. A quasistatic assumption is used to calculate the aerodynamic load of the ice quad bundle conductor. The relative wind speed is shown in Figure 2.

$F_{L i}, F_{D i}$, and $M_{i}$ are the lift force, drag force, and torque of the subconductor, respectively. Under the wind load, When the center of the bundled conductor moves horizontally, it 


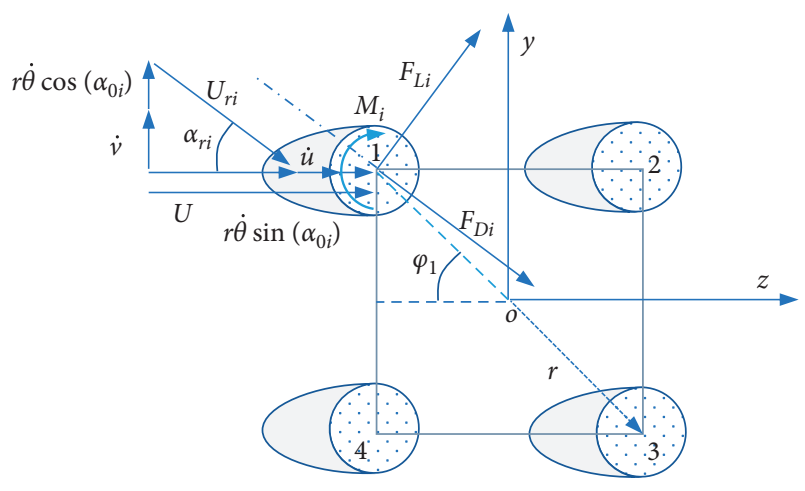

FIgURe 2: Relative wind speed.

will generate horizontal velocity $\dot{u}$, and the torsional movement of the center of the bundled conductor will also generate the horizontal velocity component $r \dot{\theta} \sin \left(\alpha_{0 i}\right)$; the relative speed of the subconductor in the horizontal direction is $U-\dot{u}-r \dot{\theta} \sin \left(\alpha_{0 i}\right)$. When the center of the bundled conductor moves vertically, it will generate vertical velocity $\dot{v}$, and the torsional movement of the center of the bundled conductor will also generate the vertical velocity component $r \dot{\theta} \cos \left(\alpha_{0 i}\right)$; the relative velocity of the subconductor in the vertical direction is $\dot{v}+r \dot{\theta} \cos \left(\alpha_{0 i}\right)$. Consequently, the relative wind speed $U_{r i}$ is

$$
U_{r i}=\sqrt{\left(\dot{v}+r \dot{\theta} \cos \left(\alpha_{0 i}\right)\right)^{2}+\left(U-\dot{u}-r \dot{\theta} \sin \left(\alpha_{0 i}\right)\right)^{2}},
$$

where $\alpha_{0 i}=\alpha_{0}+\theta+\varphi_{i}$; the relative attack angle $\alpha_{i}$ of the subconductor is

$$
\begin{aligned}
\alpha_{i} & =\alpha_{0}+\theta-\alpha_{r i}, \\
\alpha_{r i} & =\arctan \left(\frac{\dot{v}+\dot{\theta} r \cos \left(\alpha_{0 i}\right)}{U-\dot{u}-\dot{\theta} r \sin \left(\alpha_{0 i}\right)}\right),
\end{aligned}
$$

where $\alpha_{r i}$ is the change value of relative attack angle caused by the change of conductor velocity. The drag force $F_{D i}$, the lift force $F_{L i}$, and the torsional moment $M_{i}$ of subconductor can be obtained by

$$
\begin{aligned}
& F_{D i}=\frac{1}{2} \rho d U_{r i}^{2} C_{D i}\left(\alpha_{i}\right), \\
& F_{L i}=\frac{1}{2} \rho d U_{r i}^{2} C_{L i}\left(\alpha_{i}\right), \\
& M_{i}=\frac{1}{2} \rho d^{2} U_{r i}^{2} C_{M i}\left(\alpha_{i}\right),
\end{aligned}
$$

where $\rho$ is the air density and $d$ is the diameter of the subconductor. $C_{L i}, C_{D i}$, and $C_{M i}$ are the lift coefficient, drag coefficient, and torque coefficient of the subconductor, respectively; they can be obtained through wind tunnel test. Under the static wind, the subconductor at the upstream of the wind field will absorb the energy of wind and produce a wake area at the downstream of the wind field. The input wind speed of the downstream subconductor of the wind field will be lower than the input wind speed of the upstream subconductor of the wind field, and the intensity of turbulence downstream of the wind field will increase. Because of the air wake effect, the wind speed distribution is uneven, so the Aerodynamics of subconductor is different. In this paper, the influence of wake effect is considered in the study of conductor galloping stability. When calculating the dynamic response of iced conductor, the lift and drag of the subconductor need to be projected onto $z$-axis and $y$-axis. $F_{y i}, F_{z i}$, and $M_{i}$ can be obtained by

$$
F_{y i}=F_{L i} \cos \left(\alpha_{r i}\right)-F_{D i} \sin \left(\alpha_{r i}\right)=\frac{1}{2} \rho d U^{2} C_{y i}\left(U_{r i}, \alpha_{i}\right),
$$

$$
F_{z i}=F_{D i} \cos \left(\alpha_{r i}\right)+F_{L i} \sin \left(\alpha_{r i}\right)=\frac{1}{2} \rho d U^{2} C_{z i}\left(U_{r i}, \alpha_{i}\right),
$$

$$
M_{i}=\frac{1}{2} \rho d^{2} U^{2} C_{\theta i}\left(U_{r i}, \alpha_{i}\right),
$$

where $C_{y i}, C_{z i}$, and $C_{\theta i}$ are the aerodynamic coefficients of the vertical, horizontal, and torsional directions of the subconductors, which can be expressed as

$$
C_{y i}\left(U_{r i}, \alpha_{r i}\right)=\left(\frac{U_{r i}}{U}\right)^{2}\left[C_{L i}\left(\alpha_{i}\right) \cos \left(\alpha_{r i}\right)-C_{D i}\left(\alpha_{i}\right) \sin \left(\alpha_{r i}\right)\right],
$$

$$
\begin{aligned}
& C_{z i}\left(U_{r i}, \alpha_{r i}\right)=\left(\frac{U_{r i}}{U}\right)^{2}\left[C_{D i}\left(\alpha_{i}\right) \cos \left(\alpha_{r i}\right)+C_{L i}\left(\alpha_{i}\right) \sin \left(\alpha_{r i}\right)\right] \\
& C_{\theta i}\left(U_{r i}, \alpha_{r i}\right)=\left(\frac{U_{r i}}{U}\right)^{2} C_{M i}\left(\alpha_{i}\right) .
\end{aligned}
$$

Due to the influence of air wake effect, the overall wind load of a quad bundled conductor is equal to the sum of the wind loads of each subconductor. The lift force, drag force, and torque of the subconductors are translated to the center of the quad bundled conductors. According to the translation theorem, we can get

$$
\begin{aligned}
& F_{y}=\sum_{i=1}^{4} F_{y i}=\frac{1}{2} \rho d U^{2} C_{y}, \\
& F_{z}=\sum_{i=1}^{4} F_{z i}=\frac{1}{2} \rho d U^{2} C_{z}, \\
& M=\sum_{i=1}^{4}\left(M_{i}+F_{y i} r \cos \left(\alpha_{0 i}\right)+F_{z i} r \sin \left(\alpha_{0 i}\right)\right)=\frac{1}{2} \rho d^{2} U^{2} C_{\theta},
\end{aligned}
$$

where $C_{y}, C_{z}$, and $C_{\theta}$ are the whole aerodynamic coefficients of the quad bundled conductor in three directions, which can be obtained by the following formula: 


$$
\begin{aligned}
C_{y}= & \sum_{i=1}^{4} C_{y i}\left(U_{r i}, \alpha_{i}\right), \\
C_{z}= & \sum_{i=1}^{4} C_{z i}\left(U_{r i}, \alpha_{i}\right), \\
C_{\theta}= & \sum_{i=1}^{4}\left(d C_{\theta i}\left(U_{r i}, \alpha_{i}\right)+C_{y i}\left(U_{r i}, \alpha_{i}\right) r \cos \left(\alpha_{0 i}\right)\right. \\
& \left.+C_{z i}\left(U_{r i}, \alpha_{i}\right) r \sin \left(\alpha_{0 i}\right)\right) .
\end{aligned}
$$

According to Taylor's theory, the aerodynamic coefficient can be expanded at the initial attack angle $\alpha_{0}$; the linear part is as follows:

$$
\begin{aligned}
C_{y}= & \sum_{i=1}^{4}\left(C_{y i}\left(\alpha_{0}\right)+\left.\frac{\partial C_{y i}}{\partial \dot{u}_{i 1}}\right|_{\alpha_{i}=\alpha_{0}} \dot{u}_{i 1}+\left.\frac{\partial C_{y i}}{\partial \dot{v}_{i 1}}\right|_{\alpha_{i}=\alpha_{0}} \dot{v}_{i 1}+\left.\frac{\partial C_{y i}}{\partial \dot{\theta}_{1}}\right|_{\alpha_{i}=\alpha_{0}} \dot{\theta}_{1}+\left.\frac{\partial C_{y i}}{\partial \theta}\right|_{\alpha_{i}=\alpha_{0}} \theta\right), \\
C_{z}= & \sum_{i=1}^{4}\left(C_{z i}\left(\alpha_{0}\right)+\left.\frac{\partial C_{z i}}{\partial \dot{u}_{i 1}}\right|_{\alpha_{i}=\alpha_{0}} \dot{u}_{i 1}+\left.\frac{\partial C_{z i}}{\partial \dot{v}_{i 1}}\right|_{\alpha_{i}=\alpha_{0}} \dot{v}_{i 1}+\left.\frac{\partial C_{z i}}{\partial \dot{\theta}_{1}}\right|_{\alpha_{i}=\alpha_{0}} \dot{\theta}_{1}+\left.\frac{\partial C_{z i}}{\partial \theta}\right|_{\alpha_{i}=\alpha_{0}} \theta\right), \\
C_{\theta}= & \sum_{i=1}^{4}\left[d\left(C_{\theta i}\left(\alpha_{0}\right)+\left.\frac{\partial C_{\theta i}}{\partial \dot{u}_{i 1}}\right|_{\alpha_{i}=\alpha_{0}} \dot{u}_{i 1}+\left.\frac{\partial C_{\theta i}}{\partial \dot{v}_{i 1}}\right|_{\alpha_{i}=\alpha_{0}} \dot{v}_{i 1}+\left.\frac{\partial C_{\theta i}}{\partial \dot{\theta}_{1}}\right|_{\alpha_{i}=\alpha_{0}} \dot{\theta}_{1}+\left.\frac{\partial C_{\theta i}}{\partial \theta}\right|_{\alpha_{i}=\alpha_{0}} \theta\right)\right. \\
& +\left.r \cos \left(\alpha_{0 i}\right)\right|_{\theta=0}\left(C_{y i}\left(\alpha_{0}\right)+\left.\frac{\partial C_{y i}}{\partial \dot{u}_{i 1}}\right|_{\alpha_{i}=\alpha_{0}} \dot{u}_{i 1}+\left.\frac{\partial C_{y i}}{\partial \dot{v}_{i 1}}\right|_{\alpha_{i}=\alpha_{0}} \dot{v}_{i 1}+\left.\frac{\partial C_{y i}}{\partial \dot{\theta}_{1}}\right|_{\alpha_{i}=\alpha_{0}} \dot{\theta}_{1}+\left.\frac{\partial C_{y i}}{\partial \theta}\right|_{\alpha_{i}=\alpha_{0}} \theta\right) \\
& -\left.C_{y i}\left(\alpha_{0}\right) r \sin \left(\alpha_{0 i}\right)\right|_{\theta=0} \theta+\left.r \sin \left(\alpha_{0 i}\right)\right|_{\theta=0} \\
& \left.\cdot\left(C_{z i}\left(\alpha_{0}\right)+\left.\frac{\partial C_{z i}}{\partial \dot{u}_{i 1}}\right|_{\alpha_{i}=\alpha_{0}} \dot{u}_{i 1}+\left.\frac{\partial C_{z i}}{\partial \dot{v}_{i 1}}\right|_{\alpha_{i}=\alpha_{0}} \dot{v}_{i 1}+\left.\frac{\partial C_{z i}}{\partial \dot{\theta}_{1}}\right|_{\alpha_{i}=\alpha_{0}} \dot{\theta}_{1}+\left.\frac{\partial C_{z i}}{\partial \theta}\right|_{\alpha_{i}=\alpha_{0}} \theta\right)+\left.C_{z i}\left(\alpha_{0}\right) r \cos \left(\alpha_{0 i}\right)\right|_{\theta=0} \theta\right],
\end{aligned}
$$

where $\dot{u}_{i 1}=\left(\dot{u}_{i} / U\right), \dot{v}_{i 1}=\left(\dot{v}_{i} / U\right), \dot{\theta}_{1}=(\dot{\theta} r / U)$. Combining $(10 \mathrm{a})-(10 \mathrm{c})$ and $(12 \mathrm{a})-(12 \mathrm{c})$, the linear part of the whole aerodynamic load of the quad bundled conductor can be expressed as

$$
\left\{\begin{array}{c}
F_{y} \\
F_{z} \\
M
\end{array}\right\}=\sum_{i=1}^{4}\left(C_{a i}\left\{\begin{array}{c}
\dot{v}_{1} \\
\dot{u}_{1} \\
\dot{\theta}_{1}
\end{array}\right\}+K_{a i}\left\{\begin{array}{c}
v \\
u \\
\theta
\end{array}\right\}\right)+O\left(\varepsilon^{2}\right),
$$

where $\dot{u}_{1}=(\dot{u} / U), \dot{v}_{1}=\left(\dot{v}_{i} / U\right)$, and $C_{a i}$ is the aerodynamic damping matrix of subconductor, which can be expressed as

$$
C_{a i}=A\left[\begin{array}{ll}
\frac{\partial C_{y i}}{\partial \alpha_{r i}} & \frac{\partial C_{y i}}{\partial U_{r i}} \\
\frac{\partial C_{z i}}{\partial \alpha_{r i}} & \frac{\partial C_{z i}}{\partial U_{r i}} \\
a_{31} & a_{32}
\end{array}\right]\left[\begin{array}{lll}
\frac{\partial \alpha_{r i}}{\partial \dot{v}_{i 1}} & \frac{\partial \alpha_{r i}}{\partial \dot{u}_{i 1}} & \frac{\partial \alpha_{r i}}{\partial \dot{\theta}_{1}} \\
\frac{\partial U_{r i}}{\partial \dot{v}_{i 1}} & \frac{\partial U_{r i}}{\partial \dot{u}_{i 1}} & \frac{\partial U_{r i}}{\partial \dot{\theta}_{1}}
\end{array}\right],
$$

where $\quad a_{31}=\mathrm{d}\left(\partial C_{\theta i} / \partial \alpha_{r i}\right)+r \cos \left(\alpha_{0 i}\right)\left(\partial C_{y i} / \partial \alpha_{r i}\right)+r \sin$ $\left(\alpha_{0 i}\right)\left(\partial C_{z i} / \partial \alpha_{r i}\right)$ and $a_{32}=\mathrm{d}\left(\partial C_{\theta i} / \partial U_{r i}\right)+r \cos \left(\alpha_{0 i}\right)\left(\partial C_{y i} /\right.$ $\left.\partial U_{r i}\right)+r \sin \left(\alpha_{0 i}\right)\left(\partial C_{z i} / \partial U_{r i}\right), A=(1 / 2) \rho d U^{2}$.

$\mathrm{K}_{a i}$ is the subconductor load stiffness matrix, which can be expressed as

$$
K_{a i}=A\left[\begin{array}{lll}
0 & 0 & \frac{\partial C_{y i}}{\partial \theta} \\
0 & 0 & \frac{\partial C_{z i}}{\partial \theta} \\
0 & 0 & b_{33}
\end{array}\right]
$$

where $b_{33}=\mathrm{d}\left(\partial C_{\theta i} / \partial \theta\right)+\left(\partial C_{y i} / \partial \theta\right)\left(1-r \sin \left(\alpha_{0 i}\right)\right)+\left(\partial C_{z i}\right.$

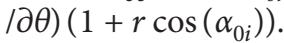

When Taylor expansion is performed at the initial angle of attack $\alpha_{0}, \dot{u}_{i 1}=\dot{v}_{i 1}=\dot{\theta}_{1}=\theta=0$. Combining (5), (6a), $(6 \mathrm{~b})$, and $(9 \mathrm{a})-(9 \mathrm{c})$, the damping matrix and stiffness matrix can be simplified to

$$
C_{a i}=A\left[\begin{array}{cc}
-C_{D i}-\frac{\partial C_{L i}}{\partial \alpha_{i}} & \frac{2}{U} C_{L i} \\
C_{L i}-\frac{\partial C_{D i}}{\partial \alpha_{i}} & \frac{2}{U} C_{D i} \\
c_{31} & c_{32}
\end{array}\right]\left[\begin{array}{ccc}
1 & 0 & \cos \left(\alpha_{0 i}\right) \\
0 & -U & -U \sin \left(\alpha_{0 i}\right)
\end{array}\right],
$$

where $c_{31}=-\mathrm{d}\left(\partial C_{M i} / \partial \alpha_{i}\right)-r \cos \left(\alpha_{0 i}\right)\left(C_{D i}+\left(\partial C_{L i} / \partial \alpha_{i}\right)\right)+$ $r \sin \left(\alpha_{0 i}\right)\left(C_{L i}-\left(\partial C_{D i} / \partial \alpha_{i}\right)\right)$ and $c_{32}=(2 / U)\left(\mathrm{dC}_{M i}+\right.$ $\left.r \cos \left(\alpha_{0 i}\right) C_{L i}+r \sin \left(\alpha_{0 i}\right) C_{D i}\right)$. 
After finishing, the damping matrix is

where

$$
C_{a i}=A\left[\begin{array}{ccc}
-\frac{\partial C_{L i}}{\partial \alpha_{i}}-C_{D i} & -2 C_{L i} & d_{13} \\
-\frac{\partial C_{D i}}{\partial \alpha_{i}}+C_{L i} & -2 C_{D i} & d_{23} \\
d_{31} & d_{32} & d_{33}
\end{array}\right]
$$

$$
\begin{aligned}
d_{13}= & \left(-\frac{\partial C_{L i}}{\partial \alpha_{i}}-C_{D i}\right) \cos \left(\alpha_{0 i}\right)-2 C_{L i} \sin \left(\alpha_{0 i}\right), \\
d_{23}= & \left(-\frac{\partial C_{D i}}{\partial \alpha_{i}}+C_{L i}\right) \cos \left(\alpha_{0 i}\right)-2 C_{D i} \sin \left(\alpha_{0 i}\right), \\
d_{31}= & -\mathrm{d} \frac{\partial C_{M i}}{\partial \alpha_{i}}-r \cos \left(\alpha_{0 i}\right)\left(C_{D i}+\frac{\partial C_{L i}}{\partial \alpha_{i}}\right)+r \sin \left(\alpha_{0 i}\right)\left(C_{L i}-\frac{\partial C_{D i}}{\partial \alpha_{i}}\right), \\
d_{32}= & -2\left(\mathrm{~d} C_{M i}+r \cos \left(\alpha_{0 i}\right) C_{L i}+r \sin \left(\alpha_{0 i}\right) C_{D i}\right), \\
d_{33}= & \cos \left(\alpha_{0 i}\right)\left(-\mathrm{d} \frac{\partial C_{M i}}{\partial \alpha_{i}}-r \cos \left(\alpha_{0 i}\right)\left(C_{D i}+\frac{\partial C_{L i}}{\partial \alpha_{i}}\right)+r \sin \left(\alpha_{0 i}\right)\left(C_{L i}-\frac{\partial C_{D i}}{\partial \alpha_{i}}\right)\right) \\
& -2 \sin \left(\alpha_{0 i}\right)\left(d C_{M i}+r \cos \left(\alpha_{0 i}\right) C_{L i}+r \sin \left(\alpha_{0 i}\right) C_{D i}\right) .
\end{aligned}
$$

The simplified stiffness matrix is

$$
K_{a i}=\frac{1}{2} \rho d U^{2}\left[\begin{array}{ccc}
0 & 0 & \frac{\partial C_{L i}}{\partial \alpha_{i}} \\
0 & 0 & \frac{\partial C_{D i}}{\partial \alpha_{i}} \\
0 & 0 & e_{33}
\end{array}\right],
$$

where $e_{33}=\mathrm{d}\left(\partial C_{M i} / \partial \alpha_{i}\right)+\left(1-r \sin \left(\alpha_{0 i}\right)\right)\left(\partial C_{L i} / \partial \alpha_{i}\right)+(1$ $\left.+r \cos \left(\alpha_{0 i}\right)\right)\left(\partial C_{D i} / \partial \alpha_{i}\right)$.

Because the model is based on quasistatic theory, the influence of the inertial coupling term and the load stiffness term on the galloping can be ignored. The balance equation of the entire whole 3-DOF iced quad bundle conductor can be expressed as

$$
M \ddot{x}+C_{d} \dot{x}+K x=\sum_{i=1}^{4} C_{a i} \dot{x}
$$

where $\quad M=\left[\begin{array}{ccc}m & 0 & 0 \\ 0 & m & 0 \\ 0 & 0 & J_{\theta}\end{array}\right], \quad K=\left[\begin{array}{ccc}K_{y} & 0 & 0 \\ 0 & K_{z} & 0 \\ 0 & 0 & K_{\theta}\end{array}\right], \quad$ and $C_{d}=\left[\begin{array}{ccc}2 m \omega_{y} \zeta_{y} & 0 & 0 \\ 0 & 2 m \omega_{z} \zeta_{z} & 0 \\ 0 & 0 & 2 J \omega_{\theta} \zeta_{\theta}\end{array}\right], \mathbf{x}=\left\{\begin{array}{c}v \\ u \\ \theta\end{array}\right\}$.

$m$ represents the mass per unit length of the quad bundle conductor. $J_{\theta}$ represents the moment of inertia. The damping ratio in the three freedom directions is $\zeta_{y}, \zeta_{z}$, and $\zeta_{\theta}$, respectively. The circular frequency in the three freedom directions is $\omega_{y}, \omega_{z}$, and $\omega_{\theta}$, respectively. According to (20), the damping matrix of the system is

$$
C=C_{d}-\sum_{i=1}^{4} C_{a i}=\left[\begin{array}{lll}
f_{11} & f_{12} & f_{13} \\
f_{21} & f_{22} & f_{23} \\
f_{31} & f_{32} & f_{33}
\end{array}\right]
$$

where 


$$
\begin{aligned}
f_{11}= & \frac{1}{2} \rho d U \sum_{i=1}^{4}\left(\frac{\partial C_{L i}}{\partial \alpha_{i}}+C_{D i}\right)+2 m \omega_{y} \zeta_{y}, \\
f_{12}= & \sum_{i=1}^{4} \rho d U C_{L i} \\
f_{21}= & \frac{1}{2} \rho d U \sum_{i=1}^{4}\left(\frac{\partial C_{D i}}{\partial \alpha_{i}}-C_{L i}\right) \\
f_{22}= & \rho d U \sum_{i=1}^{4} C_{D i}+2 m \omega_{z} \zeta_{z}, \\
f_{31}= & \frac{1}{2} \rho d U \sum_{i=1}^{4}\left(\mathrm{~d} \frac{\partial C_{M i}}{\partial \alpha_{i}}+r \cos \left(\alpha_{0 i}\right)\left(C_{D i}+\frac{\partial C_{L i}}{\partial \alpha_{i}}\right)-r \sin \left(\alpha_{0 i}\right)\left(C_{L i}-\frac{\partial C_{D i}}{\partial \alpha_{i}}\right)\right) \\
& \left.+2 \sin \left(\alpha_{0 i}\right)\left(d C_{M i}+r \cos \left(\alpha_{0 i}\right) C_{L i}+r \sin \left(\alpha_{0 i}\right) C_{D i}\right)\right)+2 J \omega_{\theta} \zeta_{\theta} \cdot \\
f_{32}= & \rho d U \sum_{i=1}^{4}\left(\mathrm{~d} C_{M i}+r \cos \left(\alpha_{0 i}\right) C_{L i}+r \sin \left(\alpha_{0 i}\right) C_{D i}\right) \\
f_{33}= & \frac{1}{2} \rho d U \sum_{i=1}^{4}\left(\cos \alpha_{0 i}\left(\mathrm{~d} \frac{\partial C_{M i}}{\partial \alpha_{i}}+r \cos \left(\alpha_{0 i}\right)\left(C_{D i}+\frac{\partial C_{L i}}{\partial \alpha_{i}}\right)-r \sin \left(\alpha_{0 i}\right)\left(C_{L i}-\frac{\partial C_{D i}}{\partial \alpha_{i}}\right)\right)\right. \\
f_{13}= & \frac{1}{2} \rho d U \sum_{i=1}^{4}\left(\left(\frac{\partial C_{L i}}{\partial \alpha_{i}}+C_{D i}\right) \cos \left(\alpha_{0 i}\right)+2 C_{L i} \sin \left(\alpha_{0 i}\right)\right) \\
f_{23}= & \frac{1}{2} \rho d U \sum_{i=1}^{4}\left(\left(\frac{\partial C_{D i}}{\partial \alpha_{i}}-C_{L i}\right) \cos \left(\alpha_{0 i}\right)+2 C_{D i} \sin \left(\alpha_{0 i}\right)\right) \\
& \\
& \\
&
\end{aligned}
$$

According to Den Hartog theory, the first coefficient of the diagonal of the matrix in (21) is the influencing factor. When the following formula is satisfied, the conductor is stable:

$$
f_{11}>0 \text {. }
$$

According to Nigol theory, the second coefficient of the diagonal of the matrix in (21) is the influencing factor. When the following formula is satisfied, the conductor is stable:

$$
f_{33}>0 \text {. }
$$

For the actual situation, the conductor will have coupled gallop in three directions. In this paper, in order to establish the system stability equation, set $x=\bar{x} e^{\beta t}$ and obtain the characteristic polynomial according to (20):

$$
G(\lambda)=\operatorname{det}\left(M \lambda^{2}+C \lambda+K\right)=\sum_{j=0}^{6} a_{j} \lambda^{6-j}
$$

The coefficients of polynomials are as follows:

$$
\begin{aligned}
& a_{0}=m^{2} J \\
& a_{1}=m^{2} f_{33}+m J f_{22}+m J f_{11} \\
& a_{2}=m^{2} J\left(\omega_{y}^{2}+\omega_{z}^{2}+\omega_{\theta}^{2}\right)+m f_{11} f_{33}+m f_{22} f_{33}+J f_{11} f_{22}, \\
& a_{3}=m^{2}\left(\omega_{y}^{2}+\omega_{z}^{2}\right) f_{33}+m J\left(\omega_{y}^{2}+\omega_{\theta}^{2}\right) f_{22}+m J\left(\omega_{z}^{2}+\omega_{\theta}^{2}\right) f_{11}+f_{11} f_{22} f_{33}, \\
& a_{4}=m^{2} J\left(\omega_{y}^{2} \omega_{z}^{2}+\omega_{y}^{2} \omega_{\theta}^{2}+\omega_{z}^{2} \omega_{\theta}^{2}\right)+m \omega_{y}^{2} f_{22} f_{33}+m \omega_{z}^{2} f_{11} f_{33}+J \omega_{\theta}^{2} f_{11} f_{22}-m f_{13} f_{31}-m f_{23} f_{32}-J f_{21} f_{12}, \\
& a_{5}=m^{2} \omega_{y}^{2} \omega_{z}^{2} f_{33}+m J \omega_{y}^{2} \omega_{\theta}^{2} f_{22}+m J \omega_{z}^{2} \omega_{\theta}^{2} f_{11}-f_{11} f_{23} f_{32}-f_{22} f_{13} f_{31}-f_{33} f_{12} f_{21}, \\
& a_{6}=m^{2} J \omega_{y}^{2} \omega_{z}^{2} \omega_{\theta}^{2}+f_{12} f_{31} f_{23}+f_{13} f_{21} f_{32}-f_{12} f_{21} m \omega_{\theta}^{2}-f_{13} f_{31} m \omega_{z}^{2} .
\end{aligned}
$$


If all roots of the characteristic polynomial $G(\lambda)$ have negative real parts, then this dynamic system is stable. According to the Routh-Hurwitz criterion, the stability condition of this dynamical system is that the coefficients of the characteristic polynomials satisfy the following condition:

$$
a_{1}>0, b_{1}>0, d_{1}>0, e_{1}>0, f_{1}>0, g_{1}>0 .
$$

where each parameter can be expressed as

$$
\begin{array}{llll}
a_{0} & a_{2} & a_{4} & a_{6} \\
a_{1} & a_{3} & a_{5} & 0 \\
b_{1}=\frac{a_{2} a_{1}-a_{0} a_{3}}{a_{1}} & b_{2}=\frac{a_{4} a_{1}-a_{0} a_{5}}{a_{1}} & b_{3}=a_{6} & 0 \\
d_{1}=\frac{a_{3} b_{1}-a_{1} b_{2}}{b_{1}} & d_{2}=\frac{a_{5} b_{1}-a_{1} b_{3}}{b_{1}} & 0 & 0 \\
e_{1}=\frac{b_{2} d_{1}-b_{1} d_{2}}{d_{1}} & e_{2}=b_{3} & 0 & 0 \\
f_{1}=\frac{d_{2} e_{1}-d_{1} e_{2}}{e_{1}} & 0 & 0
\end{array} .
$$

When the system does not meet (27), conductor galloping occurs, and the wind speed at this time is called critical wind speed. Critical wind speed can be calculated by (27).

\section{Wind Tunnel Tests}

In the previous part of the thesis, the conductor galloping model is established and the stability conditions of the conductor system are derived. When judging the stability of the system, the aerodynamic coefficient of the iced quad bundled conductor is required. In order to obtain the aerodynamic coefficient, we conducted a wind tunnel test.

3.1. Test Equipment. The test was conducted in wind tunnel with low speed. The wind tunnel is shown in Figure 3. The cross-sectional area of the test section is $1.8632 \mathrm{~m}^{2}$, the crosssectional shape is a rectangular cut-away, the length of the test section is $2.8 \mathrm{~m}$, and the wind speed is $0-65 \mathrm{~m} / \mathrm{s}$.

In this test, TG0151A and TG0151B force balances are used to measure the lift, drag, and torque of conductor model. Under natural conditions, the direction of the wind is random. In the wind tunnel test, in order to simulate the direction of natural wind as much as possible, the range of the initial attack angle that we set is $0^{\circ} \sim 180^{\circ}$. The initial angle of attack starts from $0^{\circ}$; every time aerodynamic coefficient is measured, the conductor model rotates $5^{\circ}$.
3.2. Test Model and Installation. The conductor model is shown in Figure 4. During the test, the angle of attack is changed by synchronously rotating the upper and below turntable. The layout of the subconductors of the force measuring device is shown in Figure 5. When the conductor model rotates counterclockwise, the wind direction rotates clockwise.

3.3. Test Data Processing and Result Analysis. The content of the test includes the aerodynamic coefficient of the iced quad bundled conductor at different wind speeds, different wind attack angles, different ice thicknesses, and different ice shapes. The aerodynamic coefficient is obtained by the following formula:

$$
\begin{gathered}
C_{L i}=\frac{2 F_{L i}}{\rho U^{2} L d}, \\
C_{D i}=\frac{2 F_{D i}}{\rho U^{2} L d}, \\
C_{M i}=\frac{2 M_{i}}{\rho U^{2} L d^{2}} .
\end{gathered}
$$

In the formula, $U$ is the test wind speed, and four different wind speeds are used. $L$ is the length of the conductor model, which is $700 \mathrm{~mm}$. $d$ is the diameter of the conductor model, taking $26.7 \mathrm{~mm} . \rho$ is the air density, which is $1.29 \mathrm{~kg} /$ m3.

3.3.1. Influence of Wind Speed on Aerodynamic Coefficient of Quad Bundle Conductors. In the process of wind attack angle change, the aerodynamic coefficient of subconductor 2 is almost not affected by the wake effect, so the aerodynamic coefficient of subconductor 2 is selected for the later analysis of aerodynamic characteristics. The aerodynamic coefficient of the crescent conductor with iced thickness of $12 \mathrm{~mm}$ under the wind speeds of $10,12,14$, and $18 \mathrm{~m} / \mathrm{s}$ is tested, and the test results of subconductor 2 are shown in Figure 6.

It can be seen from Figure 6 that, as the wind speed increases, the aerodynamic coefficient of conductor changes a little, so wind speed has little effect on aerodynamic coefficient.

3.3.2. Influence of Wake Effect on Aerodynamic Coefficient of Quad Bundled Conductor. The iced thickness is $20 \mathrm{~mm}$, and the wind speed is $14 \mathrm{~m} / \mathrm{s}$. The change of aerodynamic coefficient of crescent iced quad bundle conductor with attack angle is shown in Figure 7.

It can be seen from Figure 7 that the change trend of aerodynamic coefficient of each subconductor with the attack angle is approximately the same, but, due to the influence of wake effect, the aerodynamic coefficient of each subconductor will be different locally. As shown in Figure $7(a)$, the lift coefficient curve is approximately a sine function curve. It can be seen from Figure 5 that subconductor 2 is always in the upstream of the wind field during the turning for conductor model, almost not affected by the 


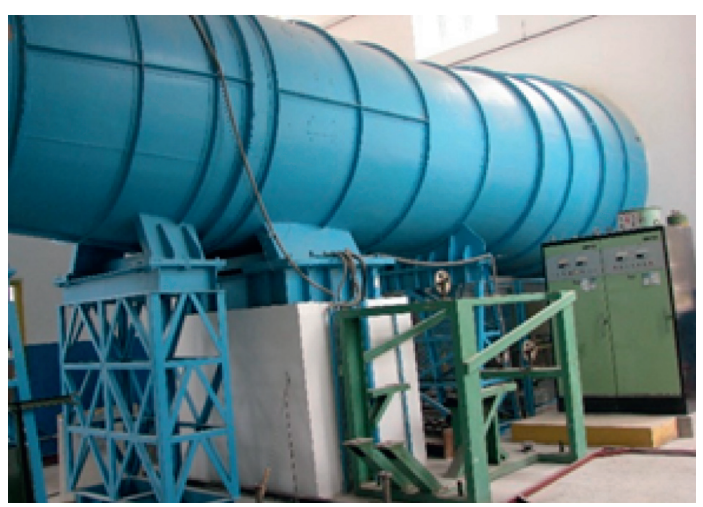

Figure 3: Wind tunnel.

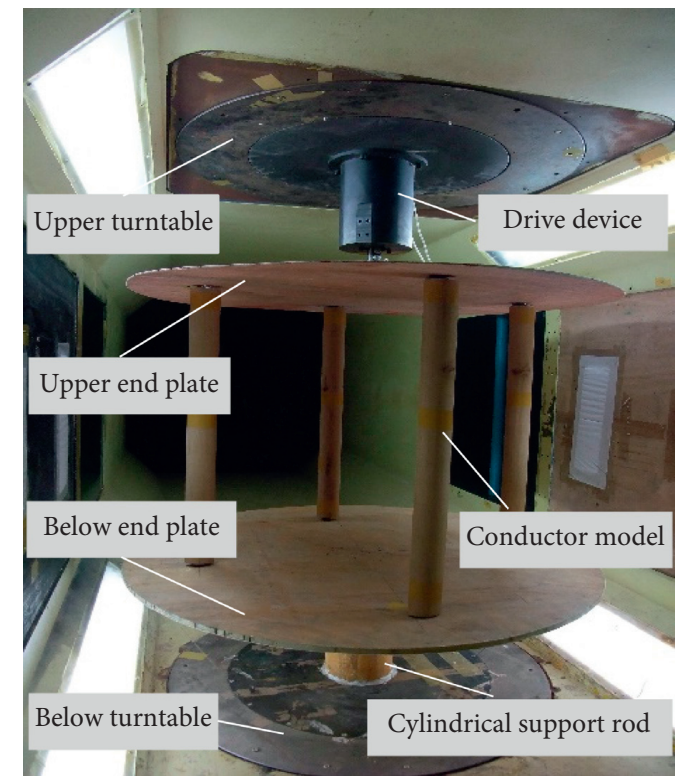

Figure 4: Model of conductor.

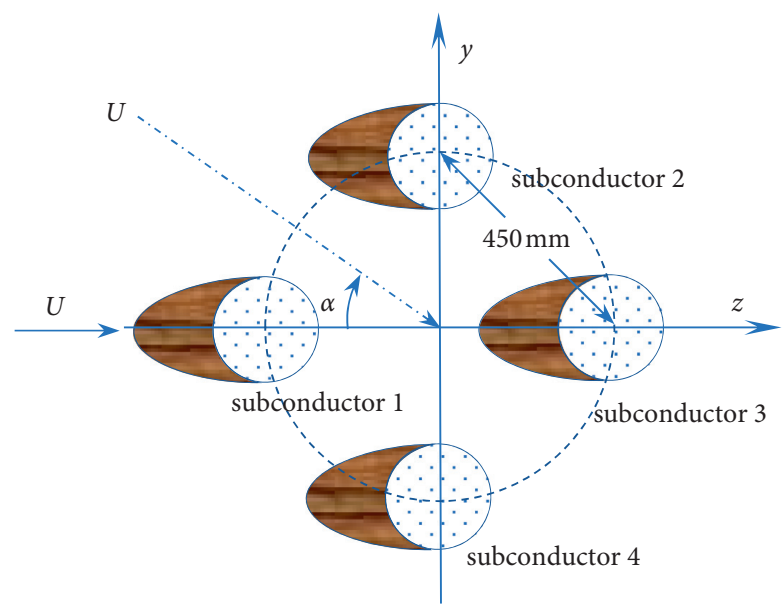

Figure 5: Layout of subconductor. 


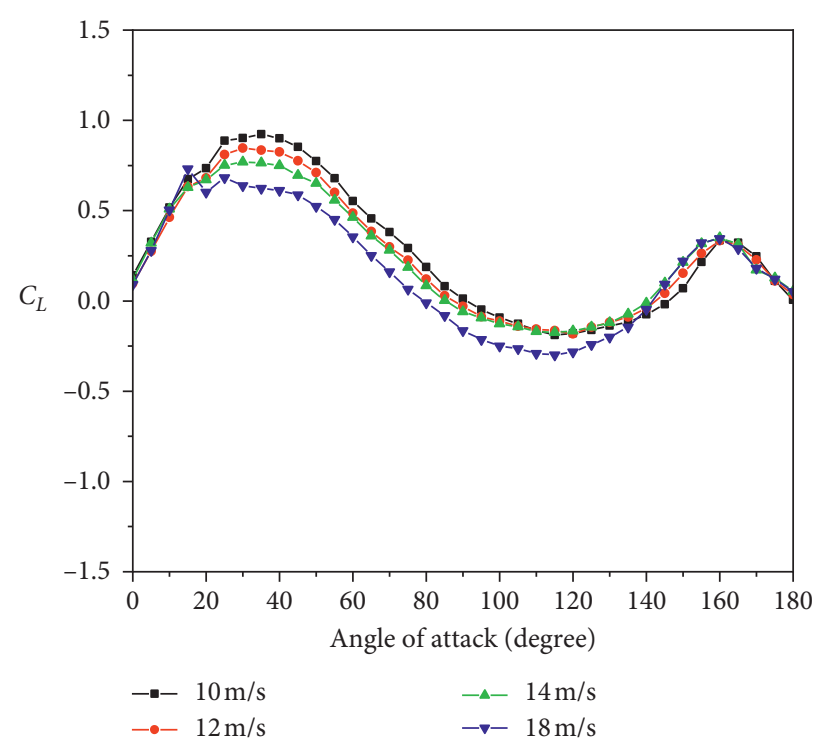

(a)

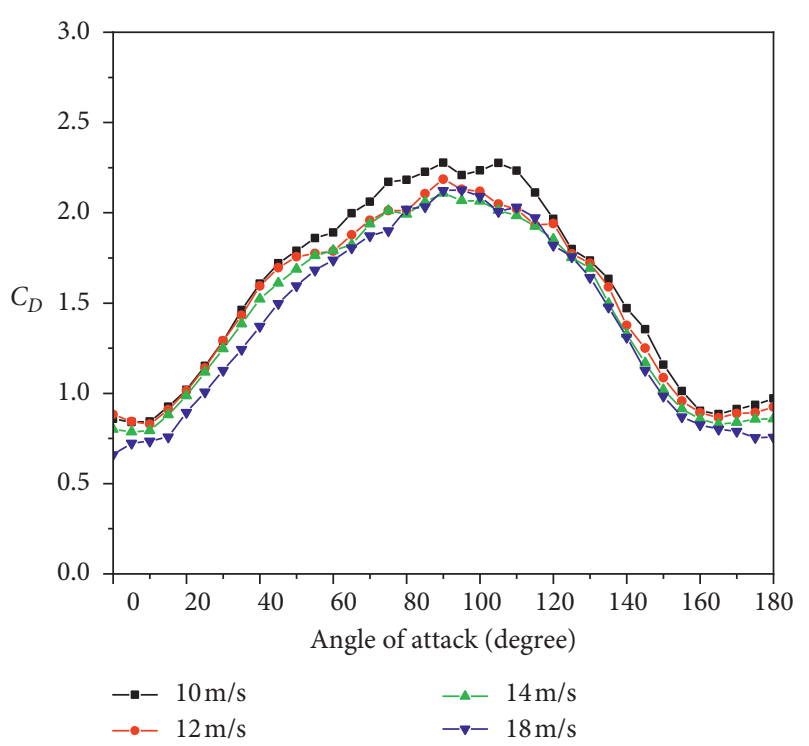

(b)

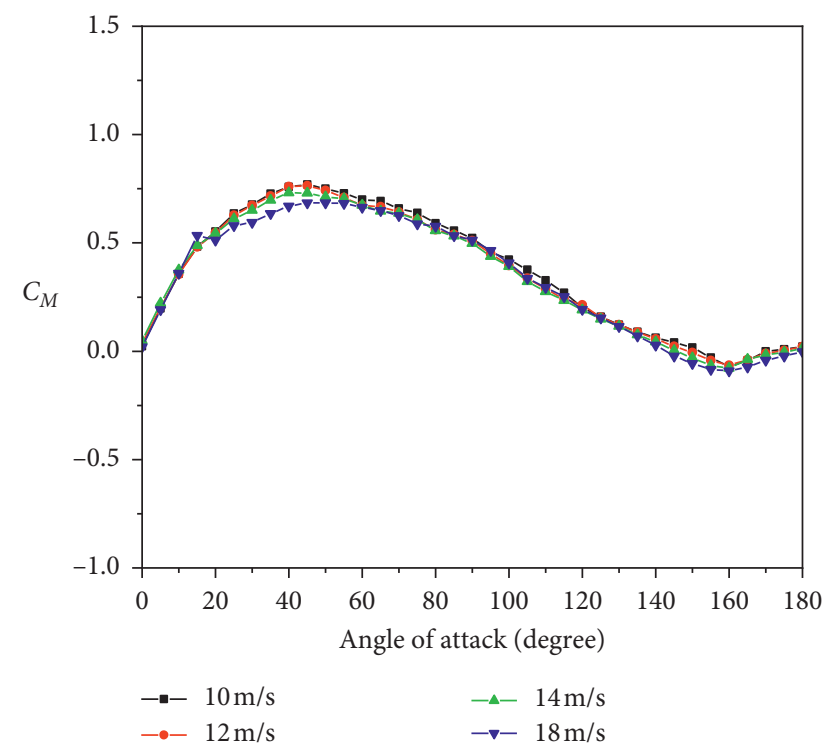

(c)

Figure 6: Comparison of aerodynamic coefficients at different wind speed. (a) Lift coefficient. (b) Drag coefficient. (c) Torque coefficient.

wake effect, and its curve of aerodynamic coefficient is relatively gentle, without mutation. When the attack angle $\alpha=0^{\circ}, \alpha=90^{\circ}$, and $\alpha=180^{\circ}$, the lift coefficient of each subconductor is almost 0. As shown in Figure 7(b), the drag coefficient curve is roughly half wave. As shown in Figure $7(\mathrm{c})$, the torque coefficient curve is approximately a sine function. When the attack angle $\alpha=0^{\circ}, \alpha=150^{\circ}$, and $\alpha=180^{\circ}$, the torque coefficient of each subconductor is almost 0 .

\subsubsection{Influence of Iced Shape on Aerodynamic Coefficient of} Quad Bundle Conductors. When the wind speed is $14 \mathrm{~m} / \mathrm{s}$ and the icing shape of the conductor is crescent shape and sector shape, the aerodynamic coefficient of the subconductor 2 is shown in Figure 8.
From Figure 8, it can be concluded that there is no uniform regulation for the influence of the shape of the ice coating on the aerodynamic coefficient of the conductor. Because different icing shapes will produce different windward areas of conductors, the aerodynamic coefficients will be different.

3.3.4. Influence of Iced Thickness on Aerodynamic Coefficient of Quad Bundle Conductors. When the wind speed is $14 \mathrm{~m} / \mathrm{s}$, the thickness of the crescent-shaped iced quad bundled conductors is 12,20 , and $28 \mathrm{~mm}$, respectively, and the aerodynamic coefficient of the subconductor 2 is shown in Figure 9.

It can be seen from Figure 9 that the thickness of the ice coating has a greater impact on the aerodynamic coefficient. 


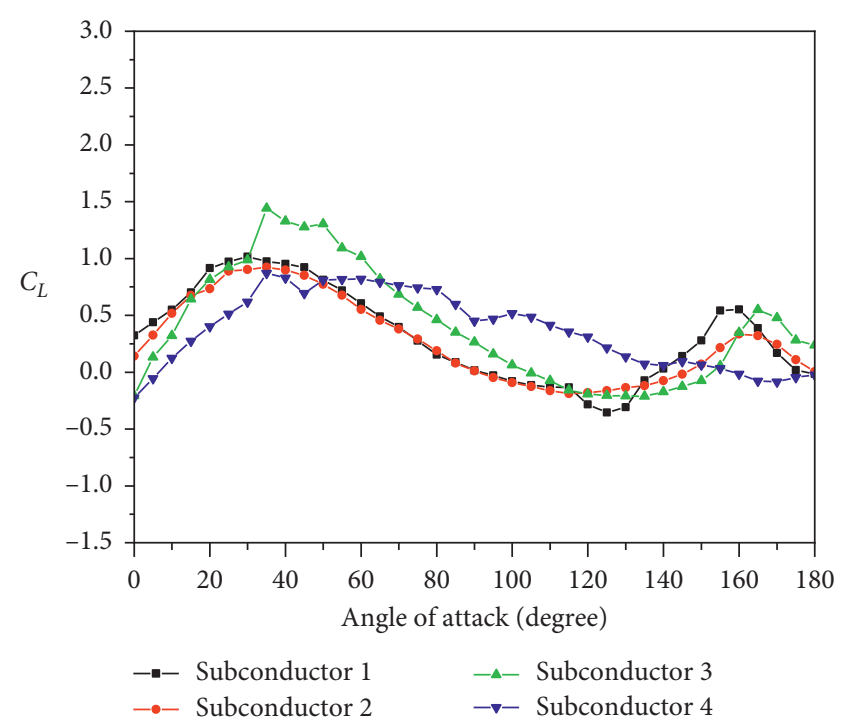

(a)

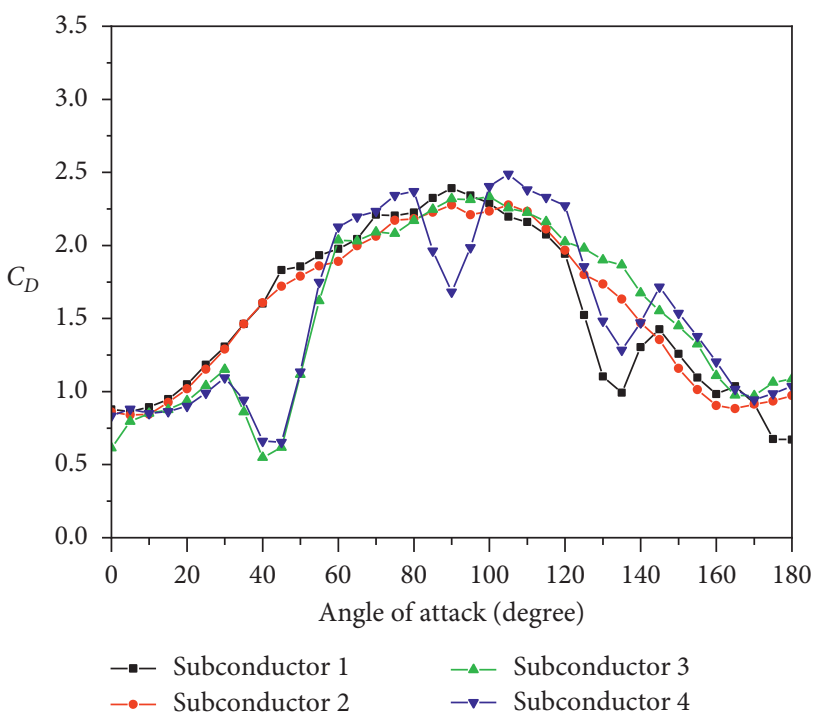

(b)

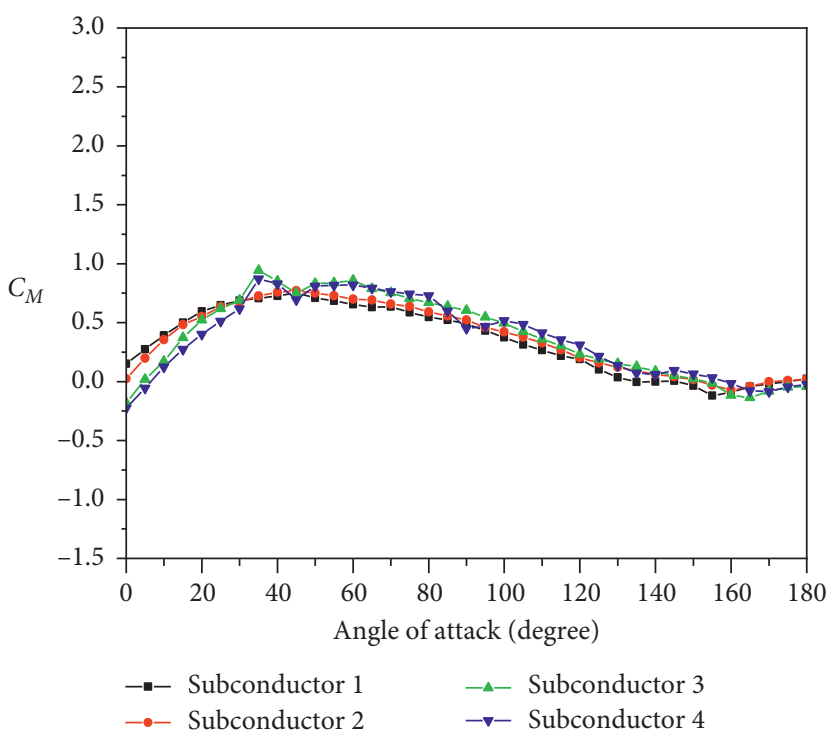

(c)

Figure 7: Comparison of aerodynamic coefficients of subconductor. (a) Lift coefficient. (b) Drag coefficient. (c) Torque coefficient.

As the ice thickness increases, the aerodynamic coefficient of the subconductor increases.

\section{Stability Calculation}

Based on the calculation theory of galloping critical wind speed, the calculation program is compiled by MATLAB. The aerodynamic coefficients obtained from the wind tunnel test in the third chapter and the conductor frequency in [24] are substituted into the stability discrimination formulas (23), (24), and (27) to calculate the critical wind speed of different galloping judgment criteria under various conditions. The parameter required for calculation is shown in Table 1.

This section will compare the critical wind speeds determined by the three stability theories. By setting variables, analyze the influence of frequency ratio, iced thickness, iced shape, and torsion frequency on stability.

4.1. Comparison of Three Different Galloping Theories. The angle of attack is $165^{\circ}$, the torsional vibration frequency is $0.4 \mathrm{~Hz}$, and crescent ice thickness is $20 \mathrm{~mm}$. The calculation result is shown in Figure 10.

It can be seen from Figure 10 that the Nigol theory critical wind speed will not change and its value is $8.6 \mathrm{~m} / \mathrm{s}$. According to formula (24), Nigol stability theory has nothing to do with frequency ratio. The critical wind speed of Den Hartog theory varies a little in the interval, and its value is between 6.1 and $6.8 \mathrm{~m} / \mathrm{s}$. The 3 -DOF theory critical wind speed decreases with the increase of frequency ratio, and its value is between 5.9 and $13.6 \mathrm{~m} / \mathrm{s}$. The frequency ratio of 1.7 is a key point. When the frequency ratio is less than 


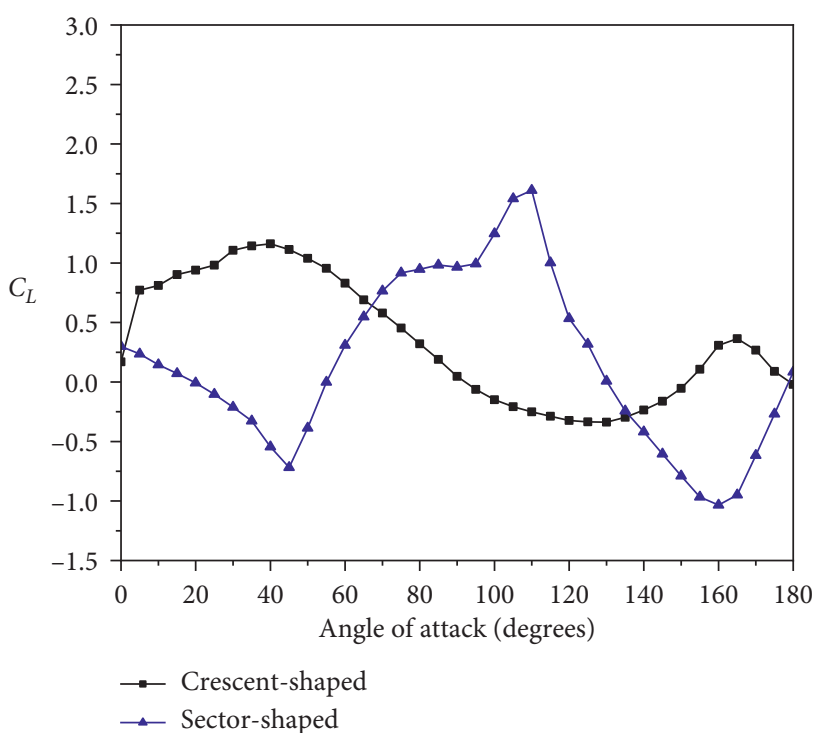

(a)

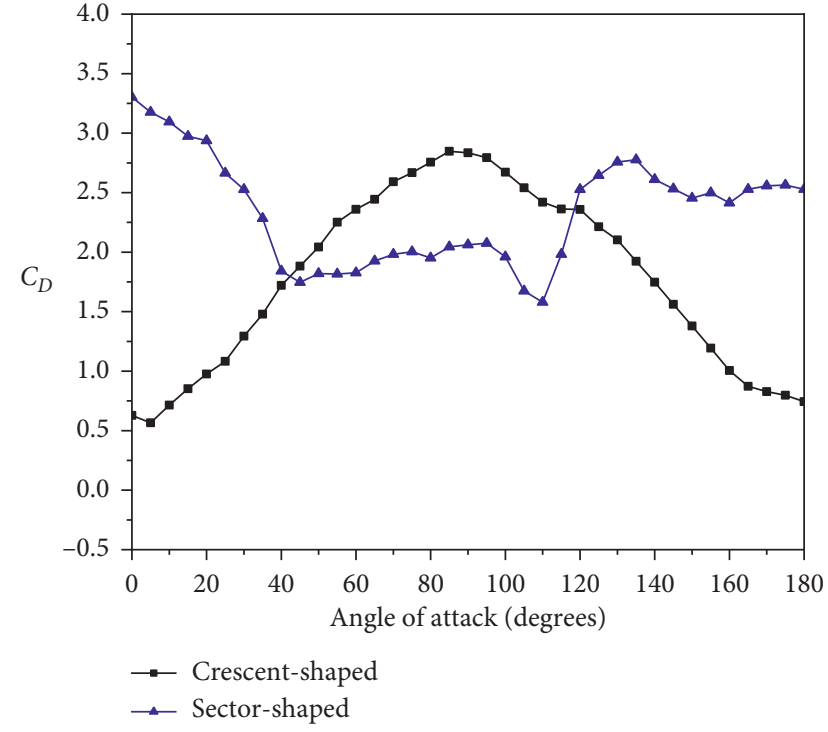

(b)

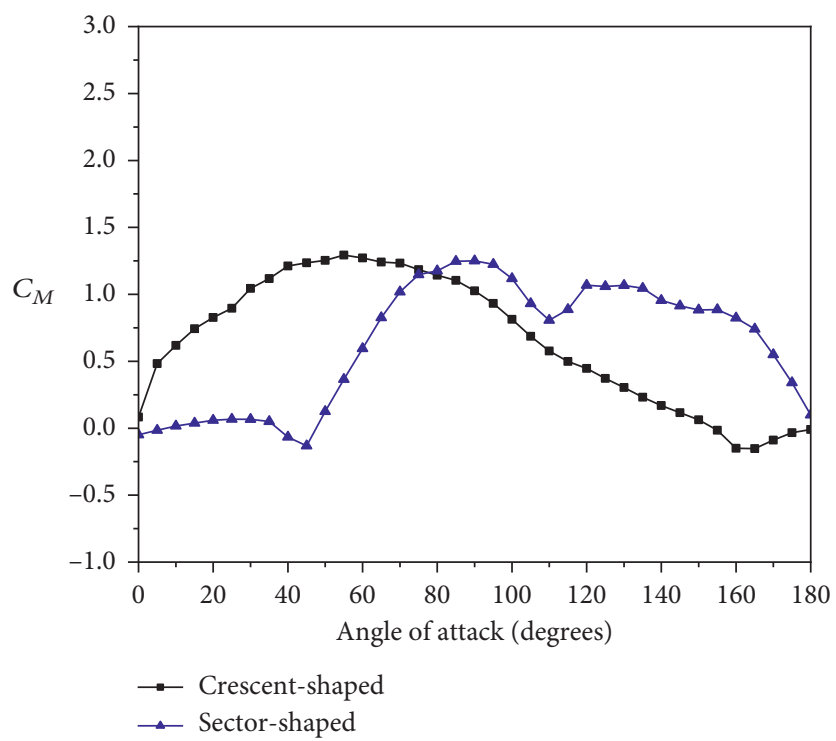

(c)

Figure 8: Comparison of aerodynamic coefficients at different iced shapes. (a) Lift coefficient. (b) Drag coefficient. (c) Torque coefficient.

1.7, the 3-DOF theory critical wind speed is greater than the critical wind speed of the two classical theories. When the ratio is greater than 1.7 , the difference of critical wind speed determined by the three theories is smaller.

4.2. Influence of Iced Thickness on Stability. When the icing shape is crescent, the torsion frequency is $0.4 \mathrm{~Hz}$ and the angle of attack is $85^{\circ}$. The stability of the conductor is judged by the 3 -DOF theory proposed in this paper. The calculation result is shown in Figure 11.

It can be seen from the Figure 11 that, with the increase of ice thickness, the critical wind speed decreases. When the ice thickness is $12 \mathrm{~mm}$ and $20 \mathrm{~mm}$, the maximum critical wind speed difference is $6.8 \mathrm{~m} / \mathrm{s}$. The ice thickness has a great influence on the impact on the stability of the conductor.
4.3. Influence of Iced Shape on Stability. When the angle of attack is $90^{\circ}$ and the torsion frequency is $0.4 \mathrm{~Hz}$, two different ice shapes are used. Use the stability theory proposed in this paper to judge the stability of the conductor, and the result is shown in Figure 12.

It can be seen from Figure 12 that the critical wind speed of the two ice-coated conductors varies with the frequency ratio. The frequency ratio equal to 1.75 is a key point. When the frequency ratio is less than 1.75 , the critical wind speed of crescent-shaped icing conductors is greater than that of sector-shaped icing conductors. When the frequency ratio is less than 1.75 , the critical wind speed of the crescent-shaped ice-coated conductors is smaller than that of the sectorshaped ice-coated conductors. There is no uniform rule for the influence of the shape of the icing on the stability of the conductors. 

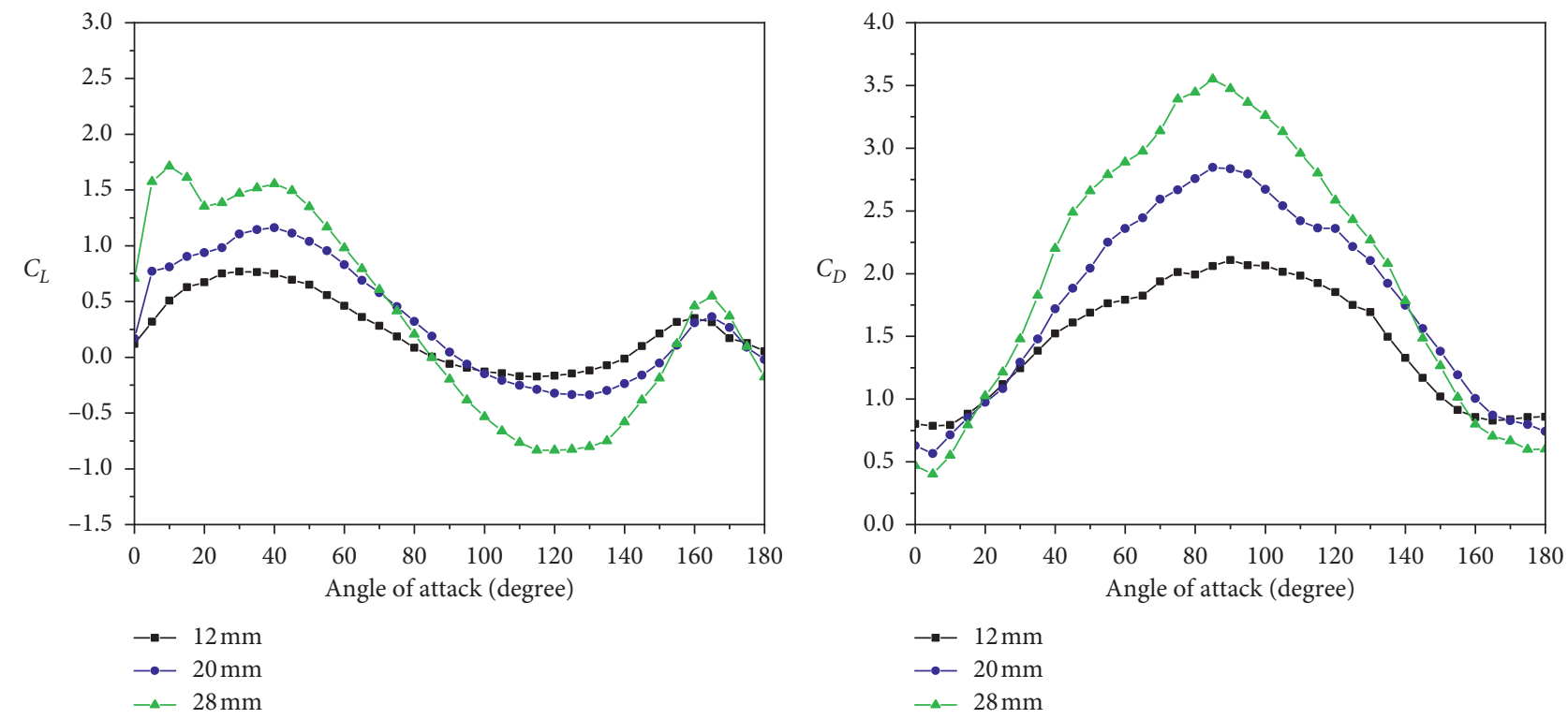

(a)

(b)

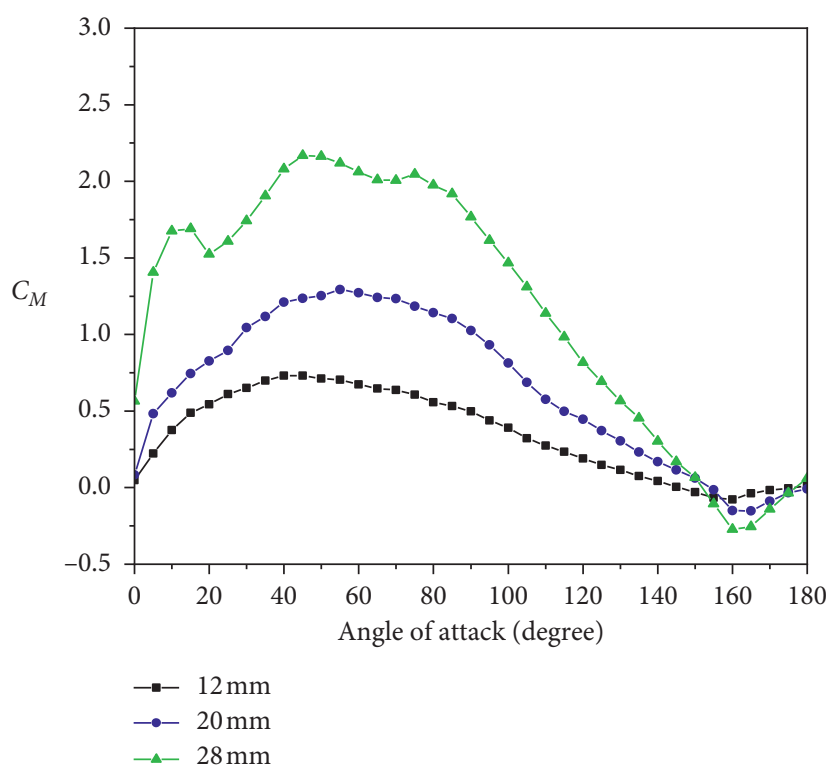

(c)

Figure 9: Comparison of aerodynamic coefficients at different iced thickness. (a) Lift coefficient. (b) Drag coefficient. (c) Torque coefficient.

TABle 1: Parameter of iced quad bundle conductors.

\begin{tabular}{|c|c|c|c|}
\hline Parameter & Symbol & Unit & Value \\
\hline Mass per unit length & $\mathrm{m}$ & $\mathrm{Kg} / \mathrm{m}^{3}$ & 8.796 \\
\hline Moment of inertia & $J_{\theta}$ & $\mathrm{kg} \mathrm{m}$ & 0.891 \\
\hline Damping ratio in $y, z$ direction & $\zeta_{y}, \zeta z$ & & 0.005 \\
\hline Damping ratio in $\theta$ direction & $\zeta_{\theta}$ & & 0.038 \\
\hline Tensile stiffness & $E A$ & $\mathrm{~N}$ & $27.64 \times 10^{6}$ \\
\hline Distance between subconductor and quad bundle conductors & $r$ & $\mathrm{~m}$ & 0.318 \\
\hline
\end{tabular}




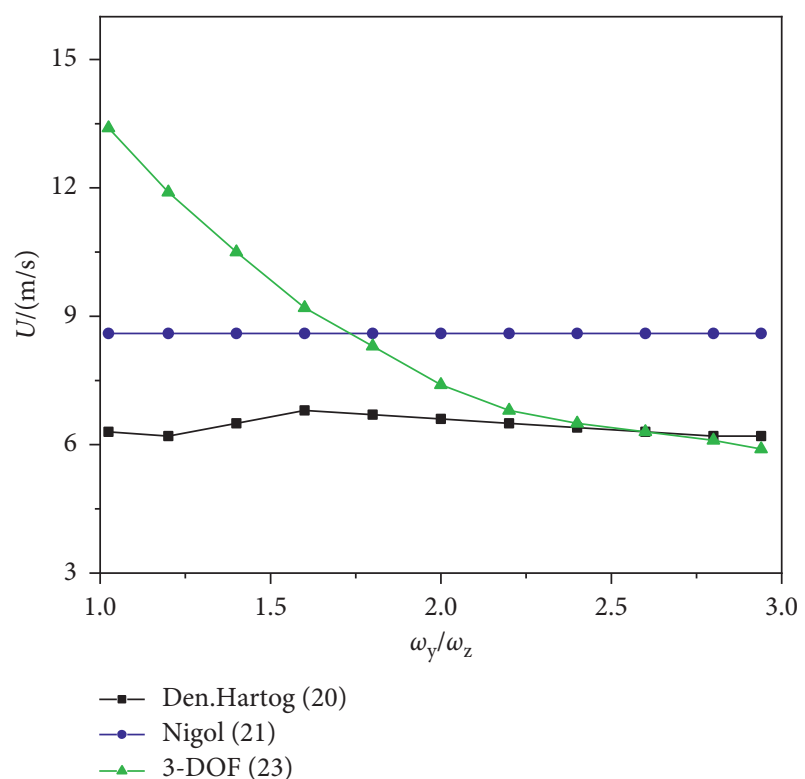

Figure 10: Comparison of critical wind speeds determined by different theories.

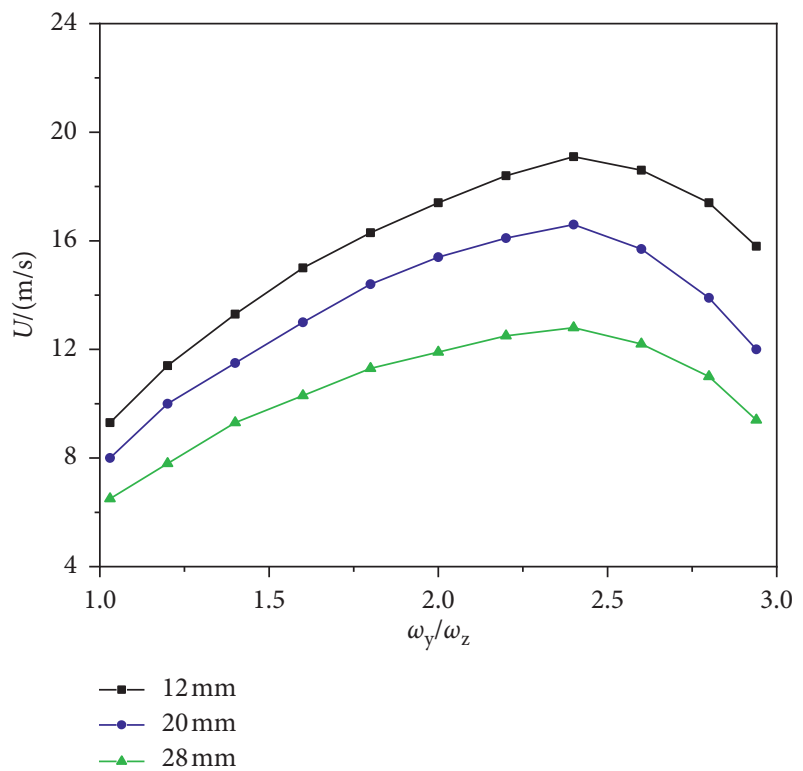

FIGURE 11: Comparison of critical wind speeds under different iced thickness.

4.4. Influence of Torsional Frequency on Stability. When the torsion frequency is $0.2 \mathrm{~Hz}, 0.4 \mathrm{~Hz}$, and $0.6 \mathrm{~Hz}$, the angle of attack is $105^{\circ}$, and the crescent-shaped ice thickness is $20 \mathrm{~mm}$. Using the 3-DOF stability theory proposed in this paper, the calculation results are shown in Figure 13.

It can be seen from Figure 13 that when the frequency ratio is the same, as the torsion frequency increases, the critical wind speed increases. When the frequency ratio is 1 , the critical wind speed difference is the largest, and the maximum value can reach $3.6 \mathrm{~m} / \mathrm{s}$. The torsion frequency will have a greater impact on the stability of the conductor.

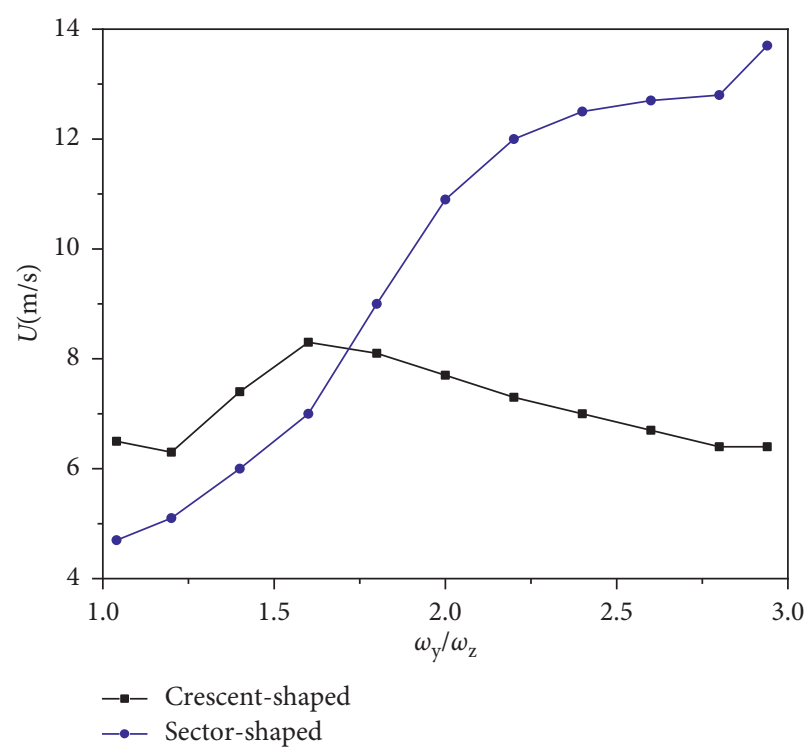

FIGURE 12: Comparison of critical wind speeds under different iced shapes.

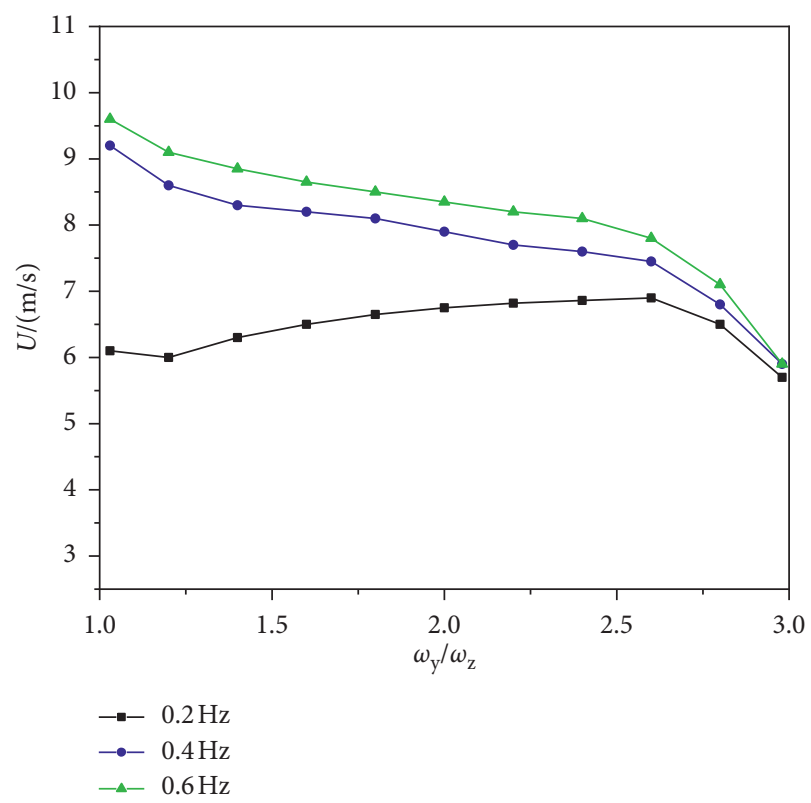

FIGURE 13: Comparison of critical wind speeds at different torsional frequencies.

\section{Conclusion}

In research, considering wake effect, the dynamic model of the 3-DOF iced quad bundled conductor is established to accurately reflect the galloping of the conductor. The wind tunnel test accurately simulated the galloping of iced quad bundled conductor under wind load. The stability criterion is used to calculate the critical wind speed under different conditions. The calculation results obtained in this paper are more accurate and reliable than those obtained by the previous method. The critical wind speed obtained in this paper can be applied to the antigalloping design of 
transmission lines under different conditions. According to the calculation results, the following conclusions can be obtained:

(1) The mechanical model of iced quad bundle conductor considers the difference of attack angle between subconductors at the same time and more truly reflects the corresponding displacement and wind load of each subconductor. The 3-DOF galloping criterion obtained by this method considers the influence of movement in three directions on the critical wind speed in detail, which is more in line with the actual engineering situation. Based on the analysis of the calculated results, it is found that, according to the Nigol criterion, the wind angles of attack at which galloping may occur are $10^{\circ}, 165^{\circ}$, and $170^{\circ}$. According to Den Hartog criterion, the wind angles of attack at which galloping may occur are $15^{\circ}, 165^{\circ}$, and $170^{\circ}$. According to the criteria proposed in this article, the wind angles of attack at which galloping may occur are $10^{\circ}, 55^{\circ}, 60^{\circ}, 70^{\circ}$, $80^{\circ}, 95^{\circ}, 165^{\circ}$, and $170^{\circ}$. Therefore, it is more accurate to use the 3-DOF stability theory to guide the wind resistant design of transmission lines.

(2) The torsional frequency has obvious influence on the stability of transmission line. With the decrease of torsion frequency, galloping is more likely to occur. Therefore, in the structural design of transmission system, the torsional frequency of transmission line system should be large.

(3) The icing thickness has an obvious influence on the stability of transmission lines. With the increase of icing thickness, galloping is more likely to occur. In the design of transmission system, anti-ice facilities should be added. The ice load should be considered in the calculation of transmission line load.

\section{Data Availability}

The data used to support the findings of this study are shown in the tables and figures of the paper.

\section{Conflicts of Interest}

The authors declare no competing interest.

\section{Acknowledgments}

This work was supported by the National Inherent Science Foundation of China and Science (Grant nos. 51308570 and 51808085), Technology Research Project of Chongqing Education Commission (Grant no. KJ201600712182), and Basics and Cutting Edge Project of Chongqing Science and Technology Commission (Grant no. cstc2017jcyjAX0246).

\section{References}

[1] F. Wang, K. Du, J. Sun, F. Huang, and Z. Xiong, "Shaking table array tests of an ultra-high-voltage cup-type transmission tower-line system," Shock and Vibration, vol. 2019, pp. 1-20, Article ID 2350675, 2019.

[2] J. P. D. Hartog, "Transmission line vibration due to sleet," Transactions of the American Institute of Electrical Engineers, vol. 51, no. 4, pp. 1074-1076, 1932.

[3] G. V. Parkinson and N. P. H. Brooks, "On the aeroelastic instability of bluff cylinders," Journal of Applied Mechanics, vol. 28, no. 2, pp. 252-258, 1961.

[4] M. Novak and A. G. Davenport, "Aeroelastic instability of prisms in turbulent flow," Journal of the Engineering Mechanics Division, vol. 96, no. 1, pp. 17-39, 1970.

[5] W. D. Iwan, "Galloping oscillations of hysteretic structures," Journal of the Engineering Mechanics Division, vol. 99, no. 6, pp. 1129-1146, 1973.

[6] O. Nigol and P. Buchan, "Conductor galloping Part I-den Hartog mechanism," IEEE Transactions on Power Apparatus and Systems, vol. 100, no. 2, pp. 699-707, 1981.

[7] P. Yu, A. H. Shah, and N. Popplewell, "Inertially coupled galloping of iced conductors," Journal of Applied Mechanics, vol. 59, no. 1, pp. 140-145, 1992.

[8] R. D. Blevins and W. D. Iwan, "The galloping response of a two-degree-of-freedom system," Journal of Applied Mechanics, vol. 41, no. 4, pp. 1113-1118, 1974.

[9] K. F. Jones, "Coupled vertical and horizontal galloping," Journal of Engineering Mechanics, vol. 118, no. 1, pp. 92-107, 1992.

[10] A. Luongo, D. Zulli, G. Piccardo et al., "On the effect of twist angle on nonlinear galloping of suspended cables," Computers \& Structures, vol. 87, no. 15-16, pp. 1003-1014, 2009.

[11] A. Luongo, D. Zulli, G. Piccardo et al., "Analytical and numerical approaches to nonlinear galloping of internally resonant suspended cables," Journal of Sound and Vibration, vol. 315, no. 3, pp. 375-393, 2008.

[12] S. C. Yang and H. P. Hong, "Nonlinear inelastic responses of transmission tower-line system under downburst wind," Engineering Structures, vol. 123, no. 123, pp. 490-500, 2016.

[13] H. Aboshosha and A. El Damatty, "Engineering method for estimating the reactions of transmission line conductors under downburst winds," Engineering Structures, vol. 99, pp. 272-284, 2015.

[14] H. Aboshosha, A. Elshaer, G. T. Bitsuamlak, and A. El Damatty, "Consistent inflow turbulence generator for LES evaluation of wind-induced responses for tall buildings," Journal of Wind Engineering and Industrial Aerodynamics, vol. 142, pp. 198-216, 2015.

[15] P. Chiradeja and A. Ngaopitakkul, "Classification of lightning and faults in transmission line systems using discrete wavelet transform," Mathematical Problems in Engineering, vol. 2018, pp. 1-14, Article ID 1847968, 2018.

[16] S. Stoyanoff, "A unified approach for 3D stability and time domain response analysis with application of quasi-steady theory," Journal of Wind Engineering and Industrial Aerodynamics, vol. 89, no. 14-15, pp. 1591-1606, 2001.

[17] D. Wu, S. Yang, L. Tao et al., "Full-scale reconstruction for transmission line galloping curves based on attitudes sensors," Mathematical Problems in Engineering, vol. 2018, pp. 1-11, Article ID 1095842, 2018. 
[18] G. Rega, N. Srinil, and R. Alaggio, "Experimental and numerical studies of inclined cables: free and parametricallyforced vibrations," Journal of Theoretical and Applied Mechanics, vol. 46, no. 3, pp. 621-640, 2008.

[19] X. Liu and B. Huo, "Nonlinear vibration and multimodal interaction analysis of transmission line with thin ice accretions," International Journal of Applied Mechanics, vol. 7, no. 1, Article ID 1550007, 2015.

[20] M. Lepidi, V. Gattulli, and F. Vestroni, "Static and dynamic response of elastic suspended cables with damage," International Journal of Solids and Structures, vol. 44, no. 25-26, pp. 8194-8212, 2007.

[21] B. Yan, X. Liu, X. Lv, and L. Zhou, "Investigation into galloping characteristics of iced quad bundle conductors," Journal of Vibration and Control, vol. 22, no. 4, pp. 965-987, 2016.

[22] X. Liu, Y. Hu, M. Cai et al., "Free vibration analysis of transmission lines based on the dynamic stiffness method," Royal Society Open Science, vol. 6, no. 3, 2019.

[23] S. Tokoro, H. Komatsu, M. Nakasu et al., "A study on wakegalloping employing full aeroelastic twin cable model," Journal of Wind Engineering and Industrial Aerodynamics, vol. 88, no. 2-3, pp. 247-261, 2000.

[24] X. Liu, L. Liu, M. Cai, and B. Yan, "Free vibration of transmission lines with multiple insulator strings using refined models," Applied Mathematical Modelling, vol. 67, pp. 252-282, 2019. 